\title{
Membranas urbanas: \\ a cena e o cenário da cidade
}

\author{
Nilberto Gomes de Sousa*
}

Resumo Partindo da segmentação dos elementos do tecido urbano, propomos fazer um caminho inverso, reunindo/constelando sob a denominação de membranas urbanas três elementos urbanos circunvizinhos: o passeio, as fachadas e os ambientes internos contíguos à fachada. Sobre estas membranas urbanas, atuam os diversos agentes urbanos buscando sanar os danos produzidos pelo urbanismo moderno. Discorremos sobre a segmentação do tecido urbano, sobre os manuais de desenho urbano e sobre o conceito de urbanidade. Buscamos afirmar as membranas urbanas como lócus privilegiado de intervenções públicas e privadas, como cena e cenário da cidade neoliberal. Estas reflexões vislumbram novas perspectivas sobre o estudo da morfologia urbana, os efeitos das edificações no urbano e as tentativas de tornar as cidades dinâmicas, sustentáveis e viáveis economicamente.

Palavras-chave: morfologia urbana, membranas urbanas, cidades.

\section{Urban membranes: the city scene and scenery}

Abstract Starting from the segmentation of urban fabric elements, the purpose is to go the inverted way, by gathering three surrounding urban elements under the name of urban membranes, these being: sidewalks, façades and indoor spaces contiguous to these façades. Several urban agents act on these urban membranes by seeking to heal damage caused by modern urbanism. The segmentation of urban fabric, urban drawing manuals and also the concept of urbanity are discussed. The aim is to affirm urban membranes as the privileged place to public and private interventions and also the scenery of neoliberal urban city. These observations glimpse new perspectives on urban morphology, the effects of urban edifications and the attempts to have dynamic, sustainable and economically viable cities.

Keywords: urban morphology, urban membranes, cities.

\section{Membranas urbanas: la escena y el esce- nario de la ciudad}

Resumen A partir de la segmentación de los elementos del tejido urbano, proponemos ir en sentido contrario, reuniendo/constelando bajo el nombre de membranas urbanas. En estas membranas urbanas, los diversos agentes urbanos actúan buscando remediar el daño producido por el urbanismo moderno. Discutimos la segmentación del tejido urbano, los manuales de diseño urbano y el concepto de urbanidad. Buscamos afirmar las membranas urbanas como el lugar privilegiado de las intervenciones la ciudad neoliberal. Estas reflexiones vislumbran nuevas perspectivas sobre el estudio de la morfología urbana, los efectos de los edificios en lo urbano y los intentos de hacer que las ciudades sean dinámicas, sostenibles y económicamente viables.

Palabras clave: morfología urbana, membranas urbanas, ciudades. 
$\mathbf{Q}$

uando nos referimos a alguns dos elementos componentes da morfologia urbana - vias, passeios, as edificações e suas fachadas - sabemos que esses apresentam segundo sua natureza e suas qualidades, significativas diferenças de permanência na cena urbana a longo prazo. É possível por meio desses elementos interpretar, em épocas distintas, as forças dos atores urbanos incidindo sobre a cidade e identificar as continuidades e rupturas entre épocas. Podemos verificar que estes elementos são periodicamente renovados pelas estratégias de melhoramento qualitativo e valorização da dinâmica dos espaços públicos. Flexibilidade e reversibilidade são os requisitos primeiros da resiliência. Aqui temos algumas razões que revelam a importância das reflexões que pretendemos expor.

A motivação deste artigo surge da observação dos trabalhos que direta ou indiretamente investigam a morfologia da cidade por meio dos seus elementos urbanos, em especial do traçado urbano e das edificações. A segmentação destes elementos nos permite investigar separadamente passeios, espaços de transição, fachadas e os ambientes internos contíguos a estas. Neste conjunto de elementos enxergamos um campo de interfaces entre o público e o privado, para o qual se voltam além das prescrições e regramentos as ações de inúmeros agentes urbanos. Chamaremos de membranas urbanas esta circunvizinhança de elementos urbanos em constante interação.

Passando pelos elementos componentes dos tecidos urbanos, pelas conceituações de urbanidade e pelos compêndios de desenho urbano, buscamos oferecer um novo olhar a respeito do conjunto de elementos urbanos sobre os quais, entendemos, os traços de arquitetos, planejadores e demais agentes urbanos objetivam corrigir, entre outras intensões, os equívocos do urbanismo moderno; promover o desenvolvimento; produzir uma cidade vivível, dinâmica e de qualidade.

Não pretendemos levantar hipóteses definitivas, pretendemos apenas iniciar as reflexões sob um ponto de vista distintos dos até então explorados e direcionar nossos olhares para um conjunto de elementos urbanos enxergados sob uma nova ótica.

* Nilberto Gomes de Sousa é Arquiteto e Urbanista, atua na Universidade Federal do Rio Grande do Norte/RN, ORCID $<$ https://orcid.org/0000-00028728-3087>.

\section{O tecido urbano esquartejado}

Com frequência as análises morfológicas da cidade separam, devido a uma necessária simplificação do conjunto que permitirá a sua leitura investigativa, os elementos componentes da sua morfologia. São exemplos dessa metodologia o olhar "arquitetônico" de Lamas (2004) que considera que os métodos de leitura serão os mesmos da arquitetura, devendo-se atentar para a maneira como essas partes se estruturam e se inter-relacionam. Estendendo seu raciocínio para a cidade, pondera ser indispensável 
Figura 1 (esquerda): Corte sobre membrana urbana. Fonte: New York Street Design Manual.

Figura 2 (direita): Indicação das zonas da membrana urbana. Fonte: Projet For Public space. Acesso 2 jul 2019. se estabelecer os elementos mínimos da forma urbana. Esses elementos urbanos mínimos começam pelo solo, seguindo com o lote (unidade de parcelamento), a quadra e o edifício, que, para ele, constituem os elementos mínimos entre todos os que preenchem a cidade e que, enquanto definidores de "limites", desenham os espaços públicos. Acrescenta o logradouro, o traçado, esse formado pelo conjunto de ruas, a praça e o monumento. Por fim, engloba também a vegetação e chega até o mobiliário urbano. Para Lang (2005) os elementos urbanos mínimos sobre os quais atuam o desenho urbano são o plano horizontal e as superfícies verticais das edificações e outros elementos físicos que os interligam e estruturam. Estes planos morfológicos horizontal e vertical configuram o binário traçado urbano-edifício, palcociclorama no qual se situa o campo de interfaces público-privado. Nosso recorte extrai do traçado a calçada, representando o espaço público; das edificações as fachadas, pertencentes ao domínio privado; os elementos híbridos - espaços de transição - que as interligam ao espaço público e os espaços internos contíguos à fachada, ou seja, os compartimentos da frente da rua. Este é o conjunto de elementos morfológicos que constituem as membranas urbanas.

Os ambientes de frente de rua fazem parte de "pleno direito" do desenho do perfil traçado-edificação, do qual constitui o primeiro tramo do edifício, sendo sua representação algo tão natural como a incontornável representação do perfil de um teatro (COELHO, COSTA, et al., 2013). Estes espaços se unem as fachadas dos edifícios como estas se ligam à rua ambos em constante interlocução, mediada pela fachada. Este fato nos leva a considera-los, sobretudo quando ao nível da calçada, espaços com forte vocação urbana. Considera-los nas reflexões sobre as membranas urbanas nos permite extrapolar a visão ortogonal limitante, da rua em planta. Nos permite compreender a "construção" das membrana como vemos representadas nas Figuras 1 e 2.

\section{INTEGRATION OF BEST MANAGEMENT PRACTICES}

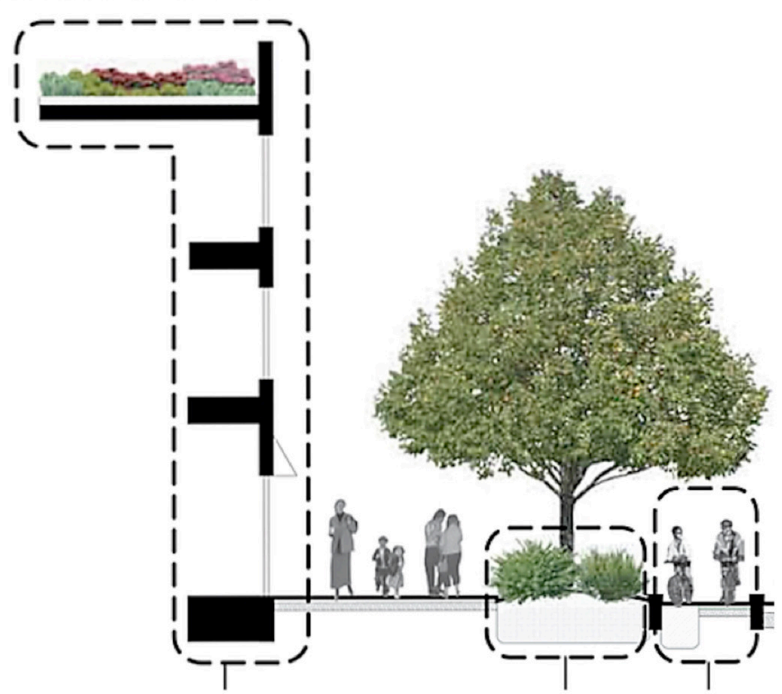

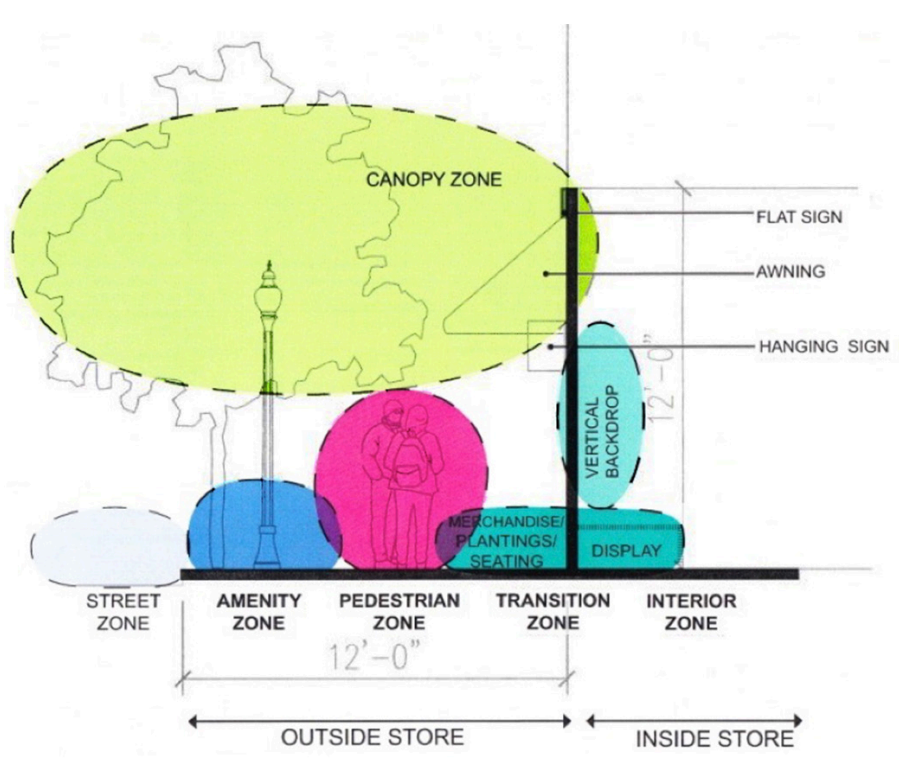




\section{Membranas urbanas}

No universo da biologia as membranas exercem diferentes funções de permeabilidade seletiva, de proteção das estruturas celulares; de delimitação do conteúdo intracelular e extracelular, garantindo a integridade da célula; de transporte de substâncias essenciais ao metabolismo celular; de reconhecimento de substâncias, graças a presença de receptores específicos na membrana. Podemos facilmente estabelecer uma analogia com os elementos urbanos - passeios, recuos, fachadas e espaços internos contíguos a esta - constituintes das membranas urbanas que desempenham algumas das funções enumeradas. As membranas urbanas filtram usuários, possibilitam a permeabilidade/conexão visual entre calçada, espaços de transição e espaços internos contíguos a fachada, delimitam o espaço público e o privado, intermediam condições climáticas, "transportam" usuários, por meio dos passeios, que se configuram como uma rede de espaços abertos e contínuos, que também permitem uma multiplicidade de usos e de situações.

As membranas urbanas são o espaço singular de continuidade, circulação, integração, transição ou barreira e contato visual entre o público e o privado. Para além da questão da propriedade, esse espaço é permeado por códigos, por regras de comportamento que permitem o estabelecimento de contato com o outro. O que, entendemos, vale tanto para o encontro entre usuários como para as interações entre edifícios, em geral privados, cujas fachadas limitam e, de certa maneira, estabelece e "filtra" a relação entre o público e o privado. Este imóvel, é ao mesmo tempo um objeto coletivo que também participa da paisagem urbana.

As membranas ao exercerem o papel de conexões e transições são fundamentais para as cidades que de certa forma existem por elas. Ambas permitem a cidade funcionar quando desempenham, as conexões, o papel de ligação ou mesmo travessias e as transições quando permitem a passagem interior/exterior. Estas conexões/transições representam elementos urbanos fundamentais por meio dos quais alguns autores a exemplo de Hillier e Hanson (1984), (2012) e Silva (2010) tentam determinar o bom ou o mau funcionamento das cidades e das intervenções nela realizadas. Vemos que a atenção dispensada as conexões e transições traduzem a preocupação de que estas sejam cuidadosamente elaboradas como elemento essenciais do tecido urbano. Suas performances, no entanto, não são avaliadas por parâmetros meramente quantitativos/ funcionais. Sua capacidade de contribuir entrelaçando áreas, dando opções de deslocamento ao usuário, promovendo o "sentido do lugar" e aproximando interior e exterior são características que contribuem para a qualidade e o caráter, variáveis subjetivas, de uma fração urbana sendo relevantes na sua avaliação.

\section{Do moderno monótono à orquestração do espetáculo}

A partir dos anos 50 iniciam-se as críticas ao "desastre urbanístico (...) do desenvolvimento urbano modernista" que, planejado pelo estado, resultará em um desenvolvimento desumanizado. As atenções gradativamente migram para uma busca de um desenvolvimento que traga as pessoas de volta às ruas. Lefebvre (1999) endossa esta crítica quando condena a supressão da rua, consequência das proposições de Le Corbusier que segundo ele teve como consequências a extinção da vida, a redução da "cidade" à condição de dormitório, levando a uma berrante funcionalização da existência. 
Nos anos setenta ocorre uma inflexão teórica sobre a cidade. A reflexão sobre espaço público e privado de desenrola segundo duas linhas dominantes. Uma sustentava o valor dos bons alinhamentos do passado como fonte definidora dos principais elementos tipológicos do tecido urbano (traçado, malha, quadras, edifícios). A segunda semelhante a primeira, na esteira da Arquitetura da Cidade (ROSSI, 2001) atribuía, as edificações singulares a definição simbólica e figurativa da cidade e sua memória histórica. Ambas as visões segundo Morales (1992), resultaram no "urbanismo desenhado" e no "urbanismo urbano". As duas posturas metodológicas intentando suplantar o zoneamento abstrato do urbanismo moderno.

À época, a crítica de Jacobs (2000) ia contra a relutância do planejamento moderno em admitir como desejáveis a concentração de pessoas e usos diversos nas cidades, a ausência da concentração e da diversidade de usos (trabalho, lazer, comércios) ou a presença insuficiente de habitantes, capazes de promover o intenso uso do solo, fatores ainda hoje largamente aceitos entre planejadores e arquitetos como indutores da vitalidade e da qualidade de vida. Argumentava ainda que essas concentrações representam os lugares mais eficazes que a sociedade ocidental engendrara até aquele momento (JACOBS, 2000).

Ainda na década de setenta inicia-se a inflexão para a acumulação flexível do capital resultante do abandono do paradigma fordista que se traduz no advento do empreendedorismo urbano e do planejamento estratégico integrado às parcerias público privadas - PPPs, como tentativa de resposta aos males causados pelo urbanismo moderno (HALL, 2009; HARVEY, 2005). Dentro do contexto do planejamento estratégico, emergente, estas novas intervenções urbanas são elaboradas para constituir uma marca que chame a atenção pelo seu esplendor. Segundo Valença (2016), o empreendedorismo urbano lança as cidades em uma espiral competitiva onde deverão constantemente produzir, por meio de intervenções urbanas, novos atributos. Estes atributos tem, ao mesmo tempo, que servir à função a que se destinam e "brilhar" na paisagem urbana. Podemos dizer que entre suas funções primordiais está a de possuir, no conjunto da intervenção e em cada edifício individualmente, um visual impactante, obtido com o concurso da grife de um arquiteto de renome por vezes aliada a uma renomada instituição ou corporação para produzir um edifício icônico.

De maneira geral, os resultados destas intervenções nos remetem à reflexão de Lefebvre (1999) sobre a colonização do espaço urbano que se concretiza, na rua, pela imagem identificada nos displays publicitários, no espetáculo do "sistema dos objetos" que vão de edificações à mobiliários urbanos tornados símbolos e espetáculo. A uniformização do novo cenário, facilmente identificável na modernização das ruas antigas, revitalizações e reurbanizações reserva a estes objetos/mercadorias uma esmerada elaboração que os tornem atraentes. Consideramos assim que o espaço público se configura como cena e cenário do espetáculo urbano almejado pelo planejamento estratégico neoliberal.

Neste movimento em direção a espetacularização do cenário urbano por vezes os arquitetos dedicam mais atenção à originalidade das suas obras do que às suas relações com a cidade. No entanto, estas relações, mesmo quando "enfraquecidas", estarão presentes no projeto por meio dos regramentos municipais. Portanto, transparecem por exemplo nos recuos obrigatórios, no estabelecimento de aberturas mínimas, na 
implantação e na definição de um volume máximo. Extrapolando o universo do lote/ edifício em si, incorporando o "urbanismo urbano" e ressoando as ideias de Jacobs, surgem algumas obras intentando fazer o papel de "drawing board", ou de compêndios de desenho urbano, com o expresso objetivo de orientar os planejadores e todos os envolvidos com a qualidade do desenho urbano na concepção ou revitalização de áreas urbanas. No Responsive environments: a manual for designs (BENTLEY, ALCOOK, et al., 1985) os autores criticam o entendimento de que a forma da cidade para muitos, parece ser apenas consequência de seus ideais políticos, na medida em que buscam identificar os atributos da forma e, elaborando um manual de desenho urbano, demonstrar que a forma urbana pode afetar as escolhas dos usuários. Para isto enumeram os principais atributos tidos como característicos da "urbanidade" e concluem: um ambiente construído deve enriquecer as oportunidades, maximizando o grau de escolhas disponíveis e tornando os lugares receptivos e compreensíveis. Em semelhante linha o Urban Design Compendium (YEANG e BAXTER, 2000) advoga que todo projeto urbano, seja para novas áreas ou para reurbanizações precisa resultar em lugares de qualidade. Que o bom desenho pode criar lugares interessantes e atrativos. "Isto significa criar áreas que sejam desejáveis, atrativas, seguras e lugares melhores para pessoas de todas as idades viverem e se desenvolver" (YEANG; BAXTER, 2000, p.9).

Nesta mesma perspectiva, mas já usufruindo das experiências concretizadas, surgiram nos últimos anos algumas publicações nas quais encontramos coletâneas de projetos e reflexões diversas. Feireiss e Hamm (2015) apresentam uma série de projetos premiados por contribuírem, de maneira nova e imaginativa, com a melhoria da qualidade de vida nas cidades europeias. Em The Fabric of Places, Allies e Morrison (2014) apresentam ensaios sobre a cidade, densidade, espaço urbano e edifícios altos, além de 17 projetos urbanos acompanhados dos conceitos, teorias e ferramentas da prática urbana para enfrentar as questões atuais. Essas obras tratam de questões como a apreciação do contexto, a diversidade, a variedade de usos e formas, a densidade, a criação de conexões, a permeabilidade e a legibilidade, entre outras. entre as quais identificamos os elementos componentes das membranas urbanas.

\section{A urbanidade: foco nas membranas urbanas}

Hillier e Hanson (1984) consideram que os arquitetos poderão produzir lugares bem estruturados e, portanto "vivíveis" utilizando-se da lógica social do espaço e tendo como ferramenta a sintaxe espacial. Em seus métodos estes autores decompõe os espaços abertos em unidades axiais e unidades convexas e as utiliza para mensurar seus padrões de relações e como, a partir destas relações, podem surgir padrões de estruturas subjacentes. Por meio desta e de outras estratégia, tem-se buscado projetar espaços que apresentem um melhor desempenho na promoção de encontros, ou seja, que induzam padrões de co-presença (SILVA, 2010).

É oportuno se perguntar que características/atributos ajudam na obtenção da urbanidade nas suas mais diversas dimensões? Neto (2012) e outros autores buscam responder a questão. Certo, concluem, é que não há consenso sobre o conceito para além da "impressão de que a urbanidade é um conceito robusto (...) que parece endereçar o coração da vida urbana e suas condições" (NETTO; AGUIAR, 2012). 
Netto (2012) discute a "urbanidade como devir do urbano", tentando aproximar os estudos urbanos da filosofia, considerando urbanidade como a "civilidade do convívio urbano" a partir da experiência social mediada pela cidade. Considera o papel integrador da cidade em "três momentos da urbanidade". O "fenomenológico" que encerra nossa experiência coletiva a partir da cidade. O "comunicativo", a cidade como palco de inter-relações simbólicas e o "ontológico" que abriga o papel da cidade na conexão entre "humano e material, entre nossas práticas e a moldagem da materialidade", o ambiente espacial que nos rodeia em forma de cidade. Conclui associando a urbanidade a um "ethos" urbano, "uma condição para a vida coletiva", acreditando que esta definição admite na urbanidade "tanto os aspectos materiais quanto os éticos". Vislumbrando um "ethos da "orientação ao Outro" (Heidengger) baseado em princípios como a comunicação livre de coerção (Habermas) e o "bem-vir às diferenças" (NETTO, AGUIAR, et al., 2012).

Aguiar (2012) explora o conceito de urbanidade enquanto "caráter urbano". Ao elencar qualidades como vitalidade e legibilidade, aproxima-se de Jacobs e Lynch e, ao considerar as pessoas interagindo com e se apropriando do espaço público onde se dão os encontros produzidos pela "axialidade" dos movimentos alinha-se com Hillier. Portanto, defende, "a urbanidade está no modo como a relação espaço/corpo se materializa" (Aguiar, 2012 apud Netto, 2012, p. 18), observando paralelamente a escala dos espaços, ou seja, sua dimensão local, e a constituição dos espaços avaliada em termos de ligações interior-exterior, dimensões que encontramos de forma sobreposta por toda a cidade destinada ao acolhimento do movimento do usuário, condição que para o autor evoca a definição de urbanidade como um "parâmetro maior, e mais abrangente, na avaliação da qualidade dos lugares" (Aguiar, 2012, apud Netto, 2012, p.18)

Para além da busca conceitual entorno da urbanidade, as respostas à "tragédia" do desenho urbano moderno incluem formulações prescritivas (BENTLEY, ALCOOK, et al., 1985; YEANG; BAXTER, 2000), métodos para sua aferição (HOLANDA, 2013; SILVA, 2010) e proposições de utilização de ferramentas informacionais para sua parametrização (SILVA, 2010). Estas diversas abordagens enumeram de forma recorrente o traçado urbano, a diversidade, a identidade, a densidade, a legibilidade, a apropriação visual, a robustez, a variedade formal e de usos como atributos necessários à geração de espaços "vivíveis", dinâmicos e de qualidade.

Identificamos entre os atributos de urbanidade acima enumerados diversos cujos lócus encontram-se nas membranas urbanas. São os casos da permeabilidade, da legibilidade, da variedade, a robustez e a apropriação visual cujos conceitos apresentamos a seguir.

Antes é indispensável lembrar que as formas construídas através de suas características morfológicas, têm seus efeitos sobre o espaço público como afirma Netto (2017). O autor ao discorrer sobre os efeitos da relação edifício-espaço público, aponta uma "causalidade parcial" entre o edifício e seus efeitos, sobre as dinâmicas das ruas, que podem ser complexa e imprevisíveis estando sujeitos a uma infinidade de fatores/condicionantes dos quais podemos ver apenas uma parte. Portanto, as características morfológicas do lugar podem interferir nas escolhas das pessoas de diferentes maneiras: a "permeabilidade" define onde as pessoas podem ir ou não; a diversidade de usos, aliada à diversidade formal que auxiliam na compreensão do lugar é definida com "legibilidade". 
Figura 3: Corte sobre membrana urbana. Fonte: Responsive environments. (Bentley, alcook, McGlynn, Murrain, \& Smith, 1985).
A permeabilidade que observamos está contida no traçado que por sua vez é intimamente ligado ao número possível de conexões no espaço público, sendo fortemente influenciada pela hierarquia deste traçado. No entanto, nos limitamos a observação dos passeios como um dos elementos constituintes das membranas urbanas. Cabe advertir que duas permeabilidades trabalham conjuntamente, à permeabilidade física e a visual. Ambas navegando por meio das membranas urbanas entre os domínios público e privado. A legibilidade é considerada pelos autores como um importante fator em relação às oportunidades e escolhas que o espaço oferece sendo importante em duas instâncias, forma física e usos.

A "robustez", aqui aplicada aos passeios, é a possibilidade de utilização de um mesmo espaço para atividades distintas. A possibilidade de usos diversos provê mais oportunidades de escolha e conforto aos seus usuários. Além de abrigar redes de infraestruturas nos passeios são instalados os mobiliários urbanos que desempenham cada um deles um papel específico na cidade. Temos os mobiliários estruturais de suporte, acessórios ou utilitários; os objetos publicitários; cabines e quiosques; a separação de meios e os elementos paisagísticos.

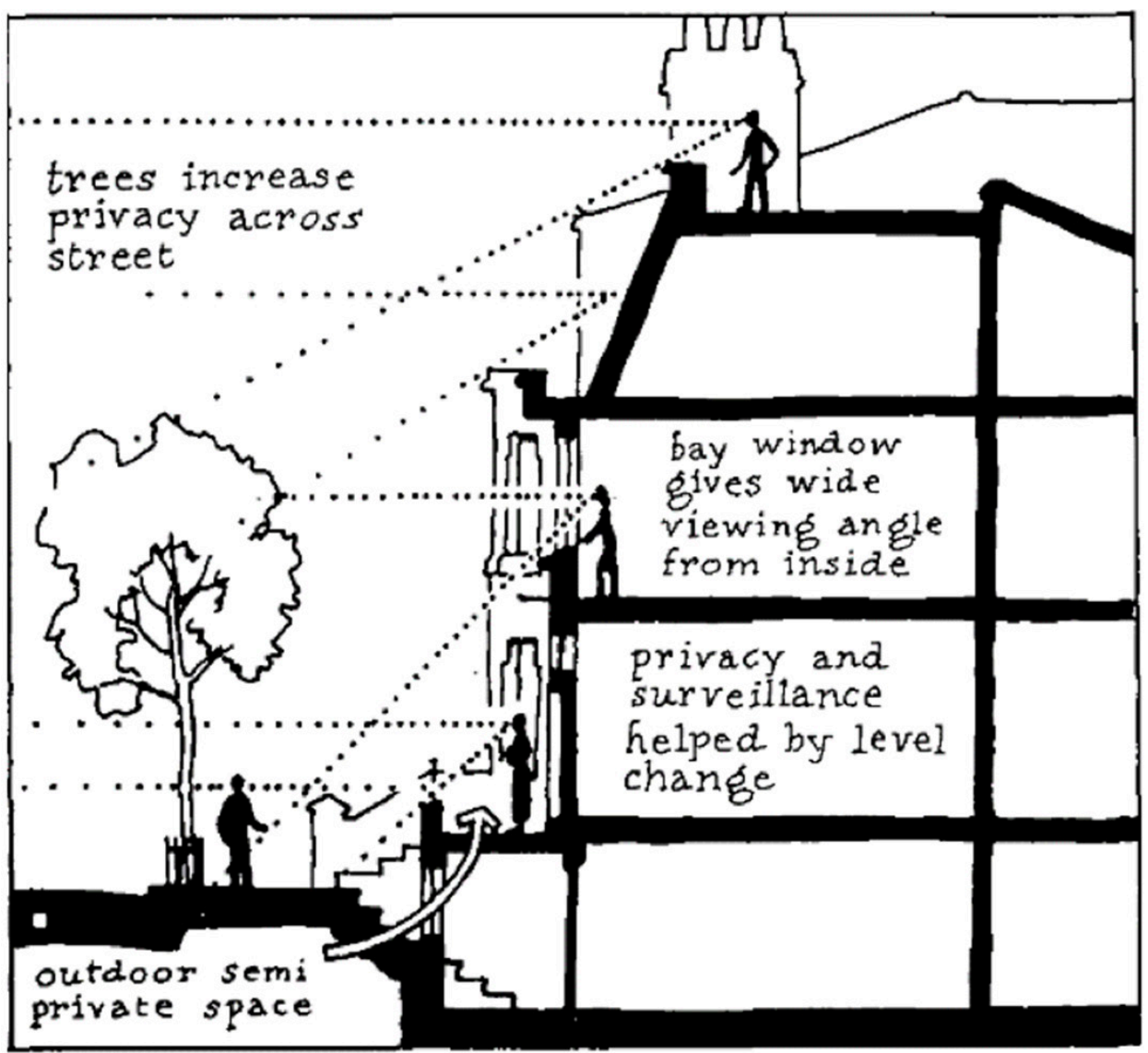


No início do Século XX, utilidade e embelezamento seriam palavras que bem qualificariam os passeios antes do surgimento do termo "urbanismo". As funções atribuídas as sistema viário - circular, servir e interligar- podem ser facilmente associadas ao longo do tempo às estratégias de melhorias e transformações deste elemento urbano que de utilitário e "decorativo" passa a ser multifuncional, versátil e adaptado as diferentes configurações do seu entorno uma vez que seus usos cotidianos entre (trocas, encontros, mobilidade, espaço de espera, café de rua, quiosques) efêmeros e variados, nunca são exatamente os mesmos, se os comparamos aos edifícios. Entre estes os dois elementos urbanos passeio-fachada existe uma relação de mútua influencia que podemos estender aos ambientes internos contíguos às fachadas. Os passeios - aliados às ruas - são ao mesmo tempo os elementos mais estáveis sendo os passeios, por outro lado, os mais mutantes ao longo do tempo. Observados juntamente com as fachadas por vezes possibilitam a "visão" das estratégias, em perpétuo movimento, que modelam as membranas.

A "apropriação visual" torna as pessoas conscientes das escolhas disponíveis. Os locais possuem a capacidade de serem visualmente apropriados desde que estre atributo permita que os usuários escolham/explorem as opções disponíveis que têm como suporte três chaves: a variedade de usos (variedade e robustez); a chave do contexto (legibilidade) e dos usuários (motivação e experiência). A "riqueza" referese a uma desejável atenção aos detalhes projetuais de maneira que a variedade de experiencias sensoriais, abrangendo todos os sentidos, seja reforçada. Portanto, mesmo considerando que para a maioria das pessoas a visão e o sentido dominante ainda resta uma larga margem para explorar sensorialmente (conforto ambiente, odores, sons) os elementos constituintes da membrana urbana para que o usuário canalize sua atenção em diferentes estímulos levando-o a se "movimentar" sensorialmente entre estes (BENTLEY, ALCOOK, et al., 1985).

Em relação à "apropriação visual" compreensão de que "a town hall should look like a town hall" (BENTLEY, ALCOOK, et al., 1985) não faz mais sentido diante da "lobotomia" (KOOLHAAS, 2008) operada entre interior e fachada na arquitetura das últimas décadas onde o "envelope" se torna independente dos ambientes e funções interiores. Portanto, a fachada não mais traduz o que ocorre no interior, se tornaram translucidamente ambíguas. Se para Koolhaas a chegada da arquitetura moderna encerra a fase de criatividade ingênua do manhattanismo, acreditamos que esta arquitetura décadas depois, e, revigorada pelas conquistas tecnológicas se inclina à um catálogo formal/facial que encarna em cada um dos seus objetos/mercadoria o outdoor "olhe para mim" um vez que mergulhados em uma fração urbana que proclama "I am a monumento" é mais difícil, exceções à parte, ser monumental. Vence a arquitetura cenográfica composta de fachadas sem conteúdo identificável.

\section{Dirigindo a cena urbana}

Fortalecer a diversidade das áreas de transição, buscar o alinhamento do lote, evitar fachadas "cegas", respeitar a privacidade, atentar para as dimensões da quadra e incentivar a utilização dos seus interiores, incrementar as conexões e tratar cuidadosamente os passeios compreendendo que estes são espaços sociais onde serviços e equipamentos são ofertados. Estas são algumas das recomendações que podemos extrair do Urban Design Compendium (YEANG; BAXTER, 2000) ás quais 
podemos somar as postas no Responsive environments (BENTLEY, ALCOOK, et al., 1985). Estamos de fato diante da produção de urbanidade ou produção do espetáculo? Ou de ambos? As questões nos remete à inquietude despertada pela afirmação de Lefebvre (1986) de que quando mais "natural", ou seja, propício ao encontro e vivível, o espaço pareça, mais ele foi modelado pelas forças que o manipulam.

As diretrizes que visam garantir espaços com intensa vitalidade, incidem sobre as membranas urbanas e as encontramos refletidas nos regramentos municipais como podemos constatar nos exemplos extraídos dos planos diretores nos capítulos dedicados ao uso e ocupação do solo. No caso de São Paulo, encontramos nas diretrizes para revisão da Legislação de Uso e Ocupação do Solo - LUOS (SÃO PAULO, 2014), no capítulo II, seção I, Art. 27 e 28, incisos referentes à permeabilidade: promover a articulação entre espaço público e espaço privado, por meio de "estímulos à manutenção de espaços abertos para fruição pública no pavimento de acesso às edificações"; referentes às fachadas que podem " estimular o comércio e os serviços locais, especificamente os instalados em fachadas ativas, com acesso direto e abertura para o logradouro"; às intervenção nas edificações para "estimular a reabilitação do patrimônio arquitetônico, especialmente na área central, criando regras e parâmetros que facilitem a reciclagem e retrofit das edificações para novos usos"; Buscando garantir o abrigo de infraestrutura demandando a reserva de "espaços para instalação de galerias para uso compartilhado de serviços públicos, inclusive centrais de produção de utilidades energéticas localizadas". Ainda no mesmo capítulo II, na seção VIII, referente aos eixos de estruturação da transformação urbana e como o objetivo de conferir qualidade urbana a estes eixos, se define alguns parâmetros e incentivos urbanísticos. Sobre as "fachadas ativas" deixa de computar 50\% da área do lote destinada ao uso não residencial contanto que se tenha um comprimento de fachada maior do que 20 metros no nível da rua e com acesso direto ao passeio. Estabelece ainda que para doação de área para alargamento das passeio, dispensa o recuo frontal sem prejuízo do potencial construtivo que continua a considerar a área total, sendo a largura mínima liberada de cinco metros nos lotes contíguos ao eixo de estruturação. Mais adiante, determina que a liberação de área para fruição pública, áreas de transição, se oferece a gratuidade sobre $50 \%$ do potencial construtivo máximo relativo à área destinada ao público, contanto que esta seja de no mínimo 250 metros quadrados e se localize ao nível do solo e tenha acesso livre permanente.

Na escala da quadra e da rua, estas medidas que buscam dinamizar a cena urbana a todo custo evitando as fachadas "mortas", aquelas que não oferecem acesso ao interior da edificação, que Yeang e Baxter (2000). No sentido de evitar membranas repelentes e suas consequências nefastas para a Urbanidade. Silva (2010) busca parametrizar nas edificações o número de aberturas, constituições, no linguajar da sintaxe espacial, entre os espaços público-privado na tentativa de se garantir, pela presença de aberturas, padrões de vitalidade/urbanidade. Com objetivos semelhantes e investigando o conjunto de qualidades desejáveis para o espaço público, Tenório

1 Project for Public Spaces (PPS) é uma organização sem fins lucrativos dedicada a ajudar os diversos agentes urbanos, pessoas especialmente, a criar espaços públicos sustentáveis que contribuam para a formação de comunidades fortes. (2012) busca responder a questão, o que faz um ótimo lugar? A resposta proposta emerge, em parte, do Project for Public Spaces ${ }^{1}$ em forma de diagrama onde a sociabilidade, os usos e atividades, acessos e integrações e o conforto e a imagem acompanhados das características inerentes a cada um dos aspectos enumerados são requisitos centrais para a obtenção de espaços públicos vivíveis e bem-sucedidos. Tenório elenca os elementos e atributos da configuração do espaço público que, do 
ponto de vista da sintaxe espacial na qual se apoia, beneficiem a vivacidade da vida pública e propõe uma metodologia para manipulação destes atributos. Novamente constatamos que estes atributos: Acessibilidade; vazios; controle das dimensões; muitas aberturas; fronteiras suaves; fachadas ativas; sensação de conforto; infraestrutura de apoio; forte identidade; símbolos marcante e lugares belos (TENÓRIO, 2012) têm como lócus as membranas urbanas.

\section{Considerações finais}

Não pretendemos desconsiderar a utilidade das metodologias que esquartejam o tecido urbano como estratégia que permite analisar separadamente seus elementos, a exemplo de Coelho (2013) ou Lang (LANG, 2005). Vemos por outro lado, a necessidade de uma análise integrada uma vez que os elementos das membranas urbanas são projetados considerando relações e intercorrências mútuas. Portanto, estes elementos podem ser "constelados", segundo a noção expressa por Benjamin (BENJAMIN, 2013), adotando-se a noção de relação entre componentes de um conjunto - membranas urbanas -, as linhas imaginárias que interligam uma constelação. Esta relação definese não apenas pela contiguidade entre elementos componentes, mas, sobretudo pelo significado que o conjunto adquire. Considerando-se estas relações e intercorrências, embora sendo seus projetos elaborados por diferentes entidades ou atores, podemos entre os elementos das membranas urbanas encontrar espaços de simbiose.

Vejamos, a título de reforço, algumas destas relações e intercorrências que expressam esta simbiose nos passeios, nas fachadas e nos ambientes internos contíguos a estas. Os passeios, para além da sua utilidade funcional primária, a separação de meios destinada à circulação, são cada vez mais estruturadas de maneira multifuncional, abrigando equipamentos, serviços, infraestruturas, espaços de convívio. Desta maneira, observamos que na calçada desempenhamos uma multiplicidade de ações, diferentemente da noção de uma casualidade conveniente, "já que estou passando por aqui aproveito para..." a calçada se tornou um destino. Assim sendo podemos considera-las em relação ao edifício, simultaneamente, um espaço servido e servidor. Também é certo que por vezes existe uma relação entre as dimensões da "caixa" do espaço público ao qual pertencem os passeios e as alturas máximas das formas edificadas. As fachadas, especialmente ao nível da calçada são em grande medida projetadas considerando alguma forma de interação com estas. Elas podem ser convidativas, preservar diferentes graus de privacidade interna, permitir acessos, estabelecer diversas interações com o espaço público e os usuários ou mesmo abrir-se configurando um espaço privado de uso público integrando-se de maneira mais ativa às dinâmicas da cidade. Os ambientes contíguos à fachada são externamente limitados por uma fina película que representa uma quase eliminação de barreiras físicas. São limites de uma bolha oxigenada com temperatura controlada cujos ambientes limítrofes declaram sua vocação urbana e clamam pelo direito ao céu, a luz e à cidade. Urbis quæ sera tamen.

O atencioso esmero dedicado ao tratamento das membranas urbanas, está, na verdade, a serviço do resgate da urbanidade ou da atmosfera de consumismo sem identidade atribuída ao capitalismo globalizado? Ou ainda, da atração de fluxos de investimentos - institucionais ou privados - indispensáveis às cidades como máquinas do crescimento? 
Se o ambiente construído deve ser eficiente e desenhado de maneira à promover o crescimento econômico local, nutrir e balizar a identidade comunitária, estas ações são sempre acompanhados de um discurso de continuidade histórica que naturaliza as mudanças e reforça a autoestima da população reforçado por um senso de justiça e democracia que estaria implícito no desenho urbano implantado.

Para além do remédio aos males atribuídos ao modernismo moderno, estaríamos diante da geminação de uma nova urbanidade? As membranas urbanas no momento atual seriam apenas mais um display de consumo, uma moldura para um supermercado a céu aberto de produtos expostos em gondolas arquitetônicas de grife?

As membranas urbanas estabelecem, portanto, uma relação cena-cenário onde vivenciamos cotidianamente episódios da interminável ópera da vida urbana. Desta maneira há sempre a possibilidade da produção de um espaço público deliberadamente orientado para uma apropriação consumista e alienante.

A partir da observação justaposta das relações e intercorrencias entre estes elementos urbanos heterogêneos como um novo objeto, acreditamos que no universo do desenho urbano cuja conceituação tradicional engloba o projeto da edificação e o planejamento urbano há, no momento em que constelamos estes elementos e aprofundarmos as investigações sobre as membranas urbanas, um espaço promissor para contribuições que lancem novas perspectivas sobre o estudo da morfologia urbana, sobre os efeitos das edificações no urbano e sobre à urbanidade, questões que rondam o universo de intervenções que pretendem remediar os males imputados ao urbanismo moderno por meio da renovação ou reconstrução de áreas específicas da cidade.

\section{Referências bibliográficas}

AGUIAR, D.; NETTO, V. M. Urbanidades. Rio de Janeiro: Letra e Imagem, 2012. (org.).

ALLIES, B.; HAIGH, D. The Fabric of Places. London: Artifice Books on Architecture, 2014.

ARANTES, O. B. F. O lugar da arquitetura depois dos modernos. São Paulo: Edusp/tudio Nobel, 1993.

BENJAMIN, W. Origem do drama trágico alemão. São Paulo: Autêntica, 2013.

BENTLEY, I. et al. Responsive environments, a manual for designers. 2005. ed. Oxford: Architectural Press, 1985

COELHO, C. D. et al. Cadernos Murb - Os elementos urbanos. Lisboa: Argumentum, v. 1, 2013.

HAMM, O. G.; FEIREISS, K. Transforming cities: urban interventions in public space. Berlin: Jovis, 2015

HILLIER, B.; HANSON, J. The Social Logic of Space. Cambridge: Cambridge University Press, 1984.

HOLANDA, F. D. O espaço de exceção. Brasília: FRBH, 2013.

JACOBS, J. Morte e vida de grandes cidades. São Paulo: Martins Fontes, 2000.

JACQUES, P. B.; PEREIRA, M. D. S. Nebulosas do pensamento urbanístico: tomo I - modos de pensar. Salvador: EDUFBA, 2018. 335 p. 
KARIMI, K. A refletion on "Order and structure in urban design". The Journal of space sintax, Londres, 3, 13 august 2012.

KOOLHAAS, R. Nova York delirante: um manifesto retroativo para manhattan. São Paulo: Casac Naif, 2008.

LAMAS, J. M. R. G. Morfologia urbana e desenho da cidade. Porto: Fundação Calouste Gulbenkian, 2004.

LANG, J. Urban design: a tipology of procedures and products. London: Architectural Press, 2005.

LEFEBVRE, H. La production de l'espace. Paris: Anthropos, 1986.

LEFEBVRE, H. A revolução urbana. Tradução de Sérgio Martins. Belo Horizonte: UFMG, 1999.

LYNCH, K. A Imagem da cidade. Tradução de Jefferson Luiz. São Paulo: Martins Fontes, 1999.

MORALES, M. D. S. Espacios públicos/espacios colctivos. La Vanguardia, Barcelona, p. 7, Maio 1992.

NETTO, V. M. O efeito da arquitettura: impactos sociais, econômicos e ambientais de diferentes configurações de quarteirão. Vitruvius, São Paulo, p. 10, 11 out 2017. Disponivel em: <http:// www.vitruvius.com.br/revistas/read/arquitextos/07.079/290>. Acesso em: 11 outubro 2017.

NETTO, V. M. et al. Urbanidades. Rio de Janeiro: Letra e Imagem, 2012.

NEW YORK CITY. High performance infrastructure guidelines. New York: NYDDC, 2005.

NEW YORK CITY. New York City department of transportation. New York: NYDT, 2015.

PANERAI, P. Análise Urbana. Tradução de Francisco Leitão. Brasília: Editora Universidade de Brasília, 2006. 198 p.

ROSSI, A. A arquitetura da cidade. São Paulo: Martins Fontes, 2001.

SALINGAROS, N. A. Principles of Urban Structure. Amsterdan: Techne Press, 2005. 252 p.

SÃO PAULO. Lei 16.050 de 31 de julho de 2014. São Paulo: [s.n.], 2014. 243 p.

SÃO PAULO. Lei n 16.402, de 22 de março de 2016. São Paulo: Diário Oficial do Município de São Paulo, 2016.

SILVA, R. C. D. Urbanismo paramétrico: parametrizando urbanidade. Recife: Ed. Universitária da UFPE, 2010

TENÓRIO, G. Ao desocupado em cima da ponte, arquitetura e vida pública. Brasília: [s.n.], 2012. 391 p. Tese (Doutorado em Arquitetura e Urbanismo) - FAculdade de Arquitetura e Urbanismo, Universidade de Brasília.

VALENÇA, M. M. Arquitetura de grife na cidade contemporânea. Tudo igual mas diferente. Rio de Janeiro: Mauad X, 2016.

VENTURI, R.; BROWN, D. S.; IZENOUR, S. Learning from Las Vegas: the forgotten symbolism of architectural form. Cambridge: MIT Press, 1977.

YEANG, L. D.; BAXTER, A. Urban Design Compendium 1. London: English Partnership, 2000. 